Historic, Archive Document

Do not assume content reflects current scientific knowledge, policies, or practices. 



\section{WHOLESALE LIST 1929 GLADIOLUS BULBS}

\section{H. SMITH}

FARIBAULT, MINN.

Prices are F. O. B. Faribault, Minn.250@1000 rate; $25 @ 100$ rate. Terms cash or $25 \%$ cash will hold order till April 1st if desired, balance to be paid before shipment. Stock has been/twice state inspected, once while growing and again in storage and is $100 \%$ clean. $90 \%$ of our Glads are grown on soil that never grew Glads before.

Bulbs quoted by the 1000 will be supplied by the 100 at 1-9 the 1000 rate. Pints and half-pints of bulblets at the quart rate. $1 / 2$ peck at the peck rate. $10 \%$ discount if order totals $\$ 50.00$ or more.

\begin{tabular}{|c|c|c|c|c|c|c|c|c|c|}
\hline \multicolumn{8}{|c|}{ Priced per 1000} & \multicolumn{2}{|c|}{ Bulblets per } \\
\hline Variety & & & 3 & 4 & 5 & 6 & 1000 & qt. & peck \\
\hline Albania $\quad \ldots \ldots \ldots \ldots \ldots \ldots . . . . . . \$ 15.00$ & $\$ 12$. & & $\$ 10.00$ & & & & $\$ .75$ & & \\
\hline Carmen Sylva ........ & 16. & & 12.00 & 10.00 & $\$ 7.00$ & $\$ 1.00$ & .75 & $\$ 3.00$ & \\
\hline Crimson Glow ........ & 16. & & 12.00 & 10.00 & 6.00 & 4.00 & .75 & 3.00 & \\
\hline Dorothy Wheeler .... 15.00 & 12. & & 10.00 & 8.00 & & & 1.00 & 2.00 & \\
\hline Elf & 16. & & 12.00 & 8.00 & 5.00 & 3.00 & .60 & 2.00 & $\$ 10.00$ \\
\hline Glendale ..................... & 16. & & 12.00 & 8.00 & 5.00 & 3.00 & .60 & 2.00 & \\
\hline Halley ...................... 10.00 & & & & & & & & .50 & 3.00 \\
\hline Jewel & 16. & & 12.00 & & & & .75 & 1.50 & \\
\hline L. M. Foch ................ & 8. & 00 & 6.00 & 4.00 & & 2.00 & .75 & .50 & 2.50 \\
\hline Maiden's Blush ........ 8.00 & 6. & 00 & 5.00 & 4.00 & 2.00 & 1.00 & & .50 & 2.50 \\
\hline Mixed & 8. & & Fine $h$ & land $\mathrm{mix}$ & xed & & & & \\
\hline Mrs. F. Pendleton .. 16.00 & 12. & 00 & 10.00 & 8.00 & 5.00 & 3.00 & .60 & 1.00 & \\
\hline Mrs. H. E. Bothin .. 18.00 & 15. & & 12.00 & 8.00 & 5.00 & 3.00 & .60 & 1.50 & 8.00 \\
\hline Mrs. F. C. Peters .. 32.00 & 26. & & 20.00 & & & & .75 & 2.50 & \\
\hline Nineteen Ten Rose.. 12.00 & & & 8.00 & 6.00 & 4.00 & 2.50 & & 1.00 & \\
\hline rinulinus Species.. 20.00 & 16. & 00 & 12.00 & 8.00 & & & .75 & & \\
\hline Peace & & 00 & 6.00 & 4.50 & 3.00 & 2.00 & & 1.00 & \\
\hline & Pric & per 1 & 100 & & & & & Bulblets & is per \\
\hline $\mathrm{V}$ & 1 & $z$ & 3 & 4 & 5 & 6 & 100 & 1000 & qt. \\
\hline Tipls & 1.40 & $\$ 1.20$ & $0 \quad \$ 1.00$ & $\$ .80$ & $\$ .60$ & $\$ .4$ & & $\$ .75$ & $\$ 1.00$ \\
\hline America & & 1.00 & .80 & .60 & .40 & .2 & & & \\
\hline Attraction, early soft red & 2.50 & & & & & & & .75 & \\
\hline ................... & 3.00 & & & & & & & .7 & \\
\hline 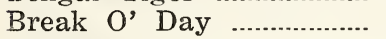 & & & 3.00 & 2.00 & 1.50 & 1.00 & & 1.25 & 5.00 \\
\hline peth $T$ & 3.50 & 2.50 & 1.80 & 1.50 & 1.00 & .75 & & .75 & \\
\hline Shaylor & 2.50 & 2.00 & & & & & & .75 & \\
\hline Giant Nymph & 4.00 & 3.20 & 2.50 & 2.00 & 1.60 & 1.20 & & .75 & \\
\hline Gold & 3.00 & 2.40 & 1.80 & & & & & .7 & \\
\hline Marshall Foc & 3.00 & & & & & & & .75 & \\
\hline .............. & 2.80 & 2.40 & 1.80 & & & & & .7 & \\
\hline Toy & 3.40 & & & & & & & .7 & \\
\hline $\begin{array}{l}\text { Mrs. Francis King } \\
\text { (slightly mixed) }\end{array}$ & 1.00 & .80 & .60 & .40 & .30 & .20 & & .50 & \\
\hline r. Mark & 2. & & & & & & & & \\
\hline rs. Newell Vanderbilt & 4.00 & & & & & & & & \\
\hline Rose Ash & 2.60 & 2.00 & & & & & & .50 & 1.50 \\
\hline on Beaut & 1.60 & & 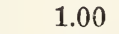 & .80 & .60 & .40 & & & 1.00 \\
\hline$\ldots \ldots \ldots \ldots$ & & 2.00 & 1. & 1.20 & & & & .75 & \\
\hline t Wond & 3.20 & 2.80 & 2.2 & 1.80 & & & & .75 & \\
\hline & 2.60 & 2.0 & 1.6 & 1.2 & 1.0 & .80 & & .60 & \\
\hline & 2.60 & 200 & 1. & 1.2 & 1.0 & & & .75 & 1.50 \\
\hline Tycko Zang & 6.00 & 5.00 & 4.00 & 3.00 & 2.00 & 1.00 & & 1.00 & \\
\hline
\end{tabular}

Prices subject to stock unsold.

On combined wholesale and retail nrders we will ship all by express and add plenty of extras to cover extra express charge on the retail part of order. 
3

. 